\title{
Sirame: Sistem Informasi Rekam Medis Klinik Bulan Sabit Merah Indonesia (BSMI) Kota Sukabumi
}

\author{
Tya Septiani Nurfauzia Koeswara ${ }^{1}$, Desi Susilawati ${ }^{2}$, Yusti Farlina ${ }^{3}$ \\ email: tya.tsf@bsi.ac.id ${ }^{1}$, desi.dlu@bsi.ac.id ${ }^{2}$, yusti.yfa@bsi.ac.id ${ }^{3}$ \\ Universitas Bina Sarana Informatika $a^{1,2,3}$
}

\begin{abstract}
Abstrak
Masyarakat membutuhkan fasilitas kesehatan dalam membantu mengobati segala macam penyakit, karena kesehatan merupakan faktor penting untuk mendukung kegiatan masyarakat sehari-hari. Salah satu fasilitas kesehatan yang masih beroperasi memberikan pelayanan kepada masyarakat yaitu klinik. Klinik Bulan Sabit Merah Indonesia (BSMI) Kota Sukabumi masih terdapat kendala dalam pengolahan data rekam medis pasien karena masih menggunakan tulis tangan di kartu rekam medis, sehingga data rawan hilang atau rusak. Sistem kearsipan belum terkomputerisasi menghambat proses pencarian dan penyimpanan data pasien. Oleh karena itu diperlukan pengembangan sistem pengelolaan data rekam medis berbasis website menggunakan metode scrum agille agar proses pengelolaan data rekam medis lebih efektif. Metode ini terdiri dari beberapa tahapan, yaitu penyusunan prioritas fitur, menyusun kegiatan, melakukan rapat dengan petugas klinik yang berkaitan dengan rekam medis dan menunjukan aplikasi yang sudah dibuat. Hasilnya sistem rekam medis Klinik Bulan Sabit Merah Indonesia (BSMI) Kota Sukabumi dapat memudahkan dalam pengelolaan data rekam medis, pencarian data dan lebih efektif dalam penyimpanan data.
\end{abstract}

Kata kunci : Sistem Informasi, Rekam Medis, Klinik

\section{Pendahuluan}

Saat ini, peran teknologi sangat berpengaruh terhadap aspek kehidupan dan profesi, salah satunya bidang kesehatan [1]. Dengan adanya teknologi, kegiatan operasional dan manajemen data dalam suatu aktivitas bisnis dapat dilakukan dengan mudah [2], termasuk juga pada klinik. Klinik merupakan fasilitas pelayanan kesehatan yang menyediakan pelayanan medis dasar atau spesialistik [3] yang masih beroperasi memberikan pelayanan kepada masyarakat [4]. Klinik terdiri dari tenaga kesehatan (perawat dan bidan) yang dipimpin oleh tenaga medis (dokter spesialis atau dokter umum). Keberadaanya sangat penting di lingkungan masyarakat, karena dapat memberikan pelayanan kesehatan dengan biaya yang cukup terjangkau [5].

Faktor penting dalam penentu kesehatan yang memiliki relevansi khusus di negaranegara berkembang adalah dengan memanfaatkan pelayanan fasilitas kesehatan tersebut [6]. Fasilitas kesehatan diperlukan untuk membantu mengobati segala macam penyakit, karena kesehatan merupakan faktor penting dalam mendukung segala aktivitas yang dilakukan [7]. Oleh karena itu upaya pengembangan sistem pelayanan kesehatan perlu ditingkatkan, terlebih dalam hal pelayanan rekam medis [8].
Rekam Medis merupakan berkas yang berisikan catatan dan dokumen tentang identitas pasien, pemeriksaan, pengobatan, tindakan dan pelayanan lain yang telah diberikan kepada pasien [3]. Proses rekam medis diawali pencatatan identitas pasien secara manual oleh resepsionis, kemudian dilakukan tindakan oleh dokter, hasil diagnosa dan tindakan dicatat manual ke dalam buku, baru dilakukan pencatatan oleh petugas rekam medis di kartu rekam medis [9]. Dari data rekam medis tersebut menghasilkan laporanlaporan dalam jangka waktu tertentu untuk dipergunakan dokter dan pimpinan klinik, rumah sakit atau puskesmas dalam mengambil keputusan [10].

Klinik Bulan Sabit Merah Indonesia Kota Sukabumi merupakan klinik faskes tingkat pertama di Kota Sukabumi yang beroperasi sejak tahun 2012. Klinik ini buka praktek untuk umum setiap pagi dan sore (seninsabtu) dengan jumlah tenaga kesehatan yang bertugas lebih dari 10 orang. Saat ini klinik BSMI Kota Sukabumi menjadi pilihan pertama bagi masyarakat sekitar untuk memeriksakan kesehatan mereka, karena biayanya cukup terjangkau. Namun masih terdapat kendala dalam hal pelayanan rekam medis pasien, karena masih dilakukan pencatatan secara manual di kartu rekam medis. Proses pencarian data pasien 
membutuhkan waktu yang lama, karena penyimpan data rekam medis masih menggunakan rak-rak arsip di ruangan tertentu. Hal tersebut dirasa kurang efektif, mengingat pelayanan merupakan faktor penting dalam bidang kesehatan, maka dibutuhkan suatu pengembangan sistem guna menangani permasalahan tersebut yaitu dengan dengan merancang sistem informasi rekam medis pada klinik Bulan Sabit Merah Indonesia (BSMI) Kota Sukabumi berbasis website dengan menerapkan metode agile development model scrum.

Kata agile berarti bersifat cepat, ringan, bebas bergerak, waspada. Kata ini digunakan sebagai kata yang menggambarkan konsep model proses yang berbeda dari konsep model-model proses yang sudah ada. Dalam Agile Software Development interaksi dan personel lebih penting dari pada proses dan alat, software yang berfungsi lebih penting daripada dokumentasi yang lengkap, kolaborasi dengan klien lebih penting daripada negosiasi kontrak, dan sikap tanggap terhadap perubahan lebih penting daripada mengikuti rencana [11]. Salah satu metodologi agile development yang sering digunakan adalah scrum, scrum dinilai menghasilkan kualitas perangkat lunak yang baik sesuai keinginan pengguna, dan dapat digunakan dalam proyek besar maupun kecil dan mudah untuk mengadopsi perubahan.

\section{Metode Penelitian}

\section{A. Teknik pengumpulan data}

Metode pengumpulan data merupakan salah satu cara untuk menyelidiki atau menguji dengan teliti dalam mencari fakta kejelasan satu permasalahan beserta pemecahan masalah [12]. Beberapa teknik dalam mengumpulkan data penelitian ini adalah:

1) Observasi

Metode ini dilakukan dengan cara pengamatan langsung dari suatu kegiatan yang dilakukan ke klinik Bulan Sabit Merah Indonesia (BSMI) Kota Sukabumi untuk mengetahui sistem rekam medis yang berjalan saat ini, sehingga dapat diperoleh data yang tepat dan akurat.

2) Wawancara

Pengumpulan data secara langsung dengan cara tanya jawab secara lisan dalam hal mendapatkan informasi, yang diwawancarai adalah petugas klinik Bulan
Sabit Merah Indonesia (BSMI) Kota Sukabumi.

3) Studi Pustaka

Pencarian data dari artikel ilmiah yang bisa berupa jurnal atau literatur-literatur lain yang berkaitan dengan program yang sedang dibuat serta beberapa komponen pendukung sistem informasi rekam medis.

\section{B. Model Pengembangan Sistem}

Model pengembangan sistem yang dipakai dalam pembuatan rancangan sistem informasi rekam medis klinik BSMI Kota Sukabumi adalah Agile Development dengan model scrum. Adapun tahapan-tahapan scrum yang dilakukan sebagai berikut:

1) Backlog

Menyusun rincian prioritas pada fitur-fitur yang akan dibangun pada sistem informasi rekam medis klinik.

2) Sprints

Menyusun kegiatan yang akan dilakukan untuk memenuhi kebutuhan yang ditetapkan dalam backlog dengan durasi realisasi selama 30 hari kerja.

3) Scrum Meeting

Menyelenggarakan rapat dengan pihak klinik BSMI Kota Sukabumi yang telah ditunjuk untuk membahas kemajuan kegiatan pengembangan sistem informasi rekam medis.

4) Demos

Menunjukkan fitur-fitur software yang telah dihasilkan untuk dievaluasi oleh pengguna sesuai dengan waktu yang telah ditentukan

\section{Hasil dan Pembahasan}

A. Tahapan Penyusunan Fitur

Pada tahap ini dilakukan analisis kebutuhan terkait fitur apa saja yang akan digunakan dalam pembuatan sistem informasi rekam medis klinik Bulan Sabit Merah Indonesia (BSMI) Kota Sukabumi.

1) Halaman Pasien

- Pasien dapat melakukan pendaftaran akun

- Pasien dapat melakukan login

- Pasien dapat melihat riwayat pengobatan

- Pasien dapat mengelola data diri

2) Halaman Dokter

- Dokter dapat melakukan login

- Dokter dapat melihat data pasien 
- Dokter dapat mengelola rekam medis

3) Halaman Admin

- Admin dapat melakukan login

- Admin dapat mengelola data dokter

- Admin dapat melihat data pasien

- Admin dapat mengelola data obat

- Admin dapat mengelola rekam medis

- Admin dapat melihat laporan

\section{B. Tahapan Kegiatan}

Setelah mengetahui fitur apa saja yang dibutuhkan dalam pembuatan sistem rekam medis klinik Bulan Sabit Merah Indonesia (BSMI) Kota Sukabumi, langkah selanjutnya yaitu eksekusi kebutuhan fitur tersebut ke dalam diagram berdasarkan database yang akan digunakan.

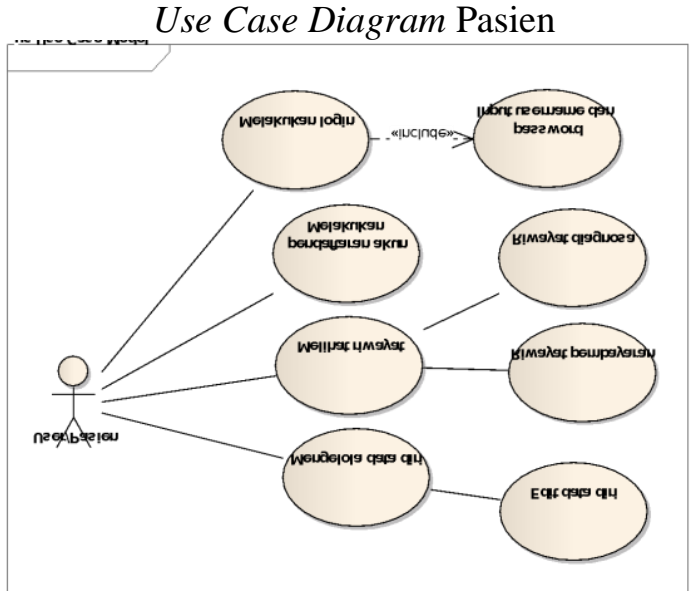

Gambar 1. Use Case Diagram Pasien

\section{Activity Diagram Kelola Rekam Medis}

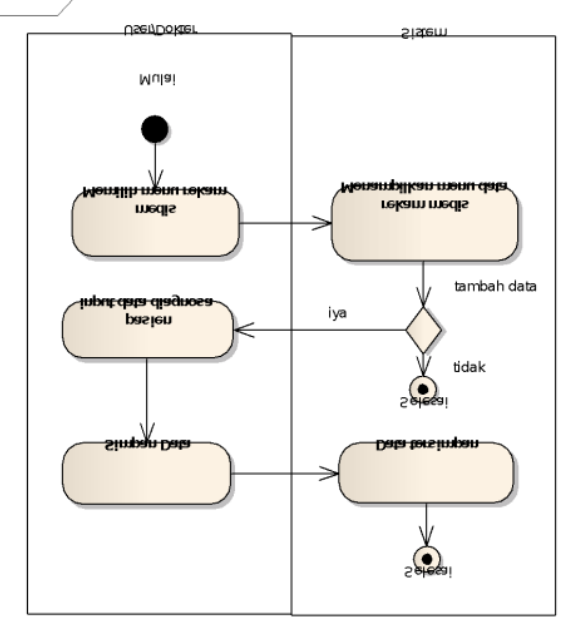

Gamber 2. Activity Diagram Kelola Rekam Medis

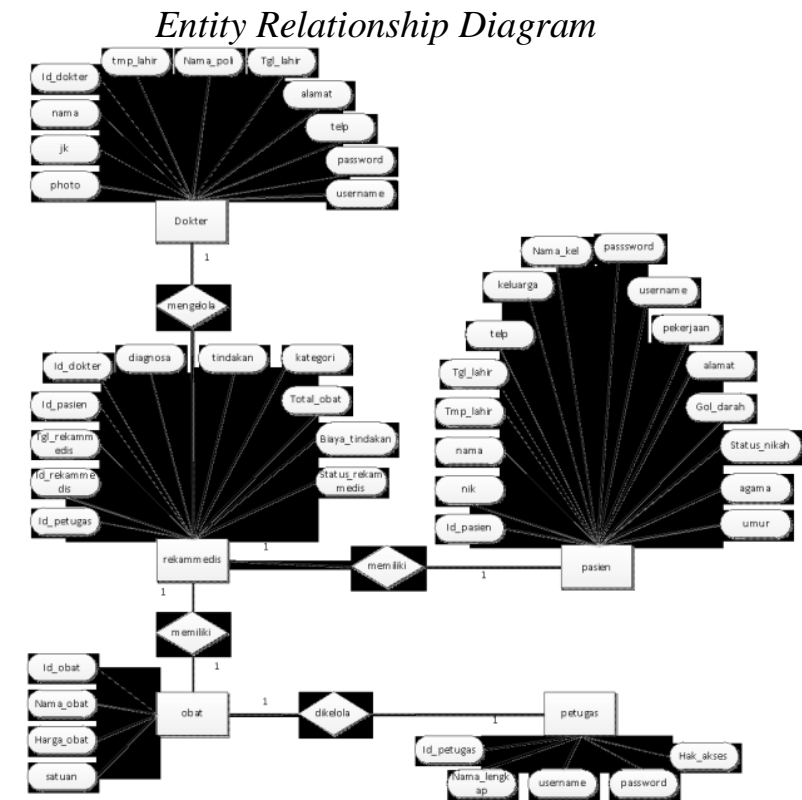

Gambar 3. Entity Relationship Diagram

\section{Diskusi Program}

Pada tahap ini dilakukan diskusi mengenai progress program berupa hak akses yang diharapkan pada saat sistem rekam medis klinik Bulan sabit Merah Indonesia (BSMI) Kota Sukabumi dijalankan. Selengkapnya dapat dilihat pada tabel berikut:

Tabel 1. Hak Akses Pasien

\begin{tabular}{llll}
\hline Login & $\begin{array}{l}\text { Daftar } \\
\text { Akun }\end{array}$ & $\begin{array}{l}\text { Lihat } \\
\text { Riwayat }\end{array}$ & $\begin{array}{l}\text { Kelola } \\
\text { Data } \\
\text { Diri }\end{array}$ \\
\hline$\sqrt{ }$ & $\sqrt{ }$ & $\sqrt{ }$ & $\sqrt{ }$ \\
\hline
\end{tabular}

Tabel 2. Hak Akses Dokter

\begin{tabular}{lll}
\hline Login & $\begin{array}{l}\text { Lihat Data } \\
\text { Pasien }\end{array}$ & $\begin{array}{l}\text { Kelola } \\
\text { Rekam } \\
\text { Medis }\end{array}$ \\
\hline$\sqrt{ }$ & $\sqrt{ }$ & $\sqrt{ }$ \\
\hline
\end{tabular}

Tabel 3. Hal Akses Admin

\begin{tabular}{|c|c|c|c|c|c|}
\hline Login & $\begin{array}{l}\text { Kelola } \\
\text { Data } \\
\text { Dokter }\end{array}$ & $\begin{array}{l}\text { Lihat } \\
\text { Data } \\
\text { Pasien }\end{array}$ & $\begin{array}{l}\text { Kelola } \\
\text { Data } \\
\text { Obat }\end{array}$ & $\begin{array}{l}\text { Kelola } \\
\text { Rekam } \\
\text { Medis }\end{array}$ & Laporan \\
\hline$\sqrt{ }$ & $\sqrt{ }$ & $\sqrt{ }$ & $\sqrt{ }$ & $\sqrt{ }$ & $\sqrt{ }$ \\
\hline
\end{tabular}

D. Implementasi Program

1) Spesifikasi Hardware

- CPU Processor AMD A10-5800K, RAM 2,00 GB, Harddisk 550 GB

- Mouse

- Keyboard

- Monitor dengan resolusi layar minimum 1028x768 
- Koneksi internet dengan kecepatan 2Mbps

2) Spesifikasi Software

- Sistem operasi yang umum digunakan seperti Microsoft Windows 7

- Aplikasi bundle web server seperti XAMPP, WampServer, php2triad

- Aplikasi web seperti Mozilla Firefox, Opera, Internet Explore, Google Chrome

3) Rancangan Antarmuka

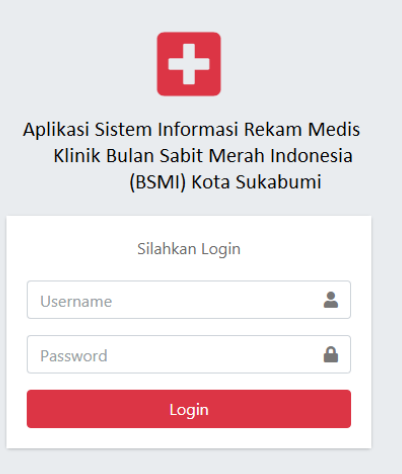

Gambar 4. Rancangan Antarmuka Login

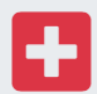

Aplikasi Sistem Informasi Rekam Medis Klinik Bulan Sabit Merah Indonesia (BSMI) Kota Sukabumi

\section{FORM REGISTRASI \\ Silahkan Lengkapi Data Berikut Ini}

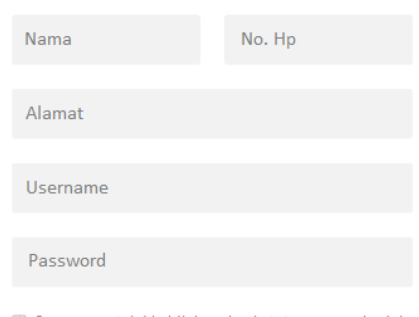

Daftar

Sudah mempunyai akun ? klik Login

Gambar 5. Rancangan Antarmuka Registrasi Akun 


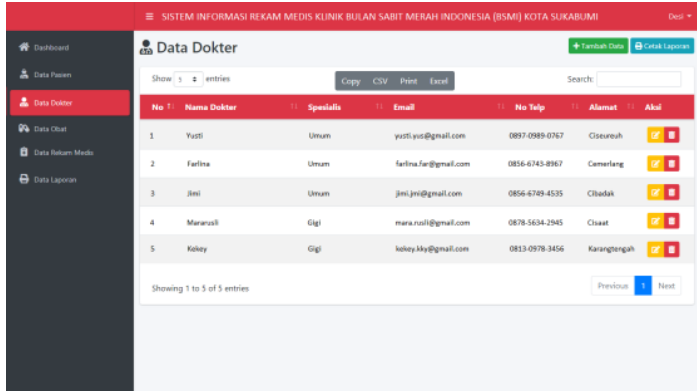

Gambar 11. Rancangan Antarmuka Data Dokter

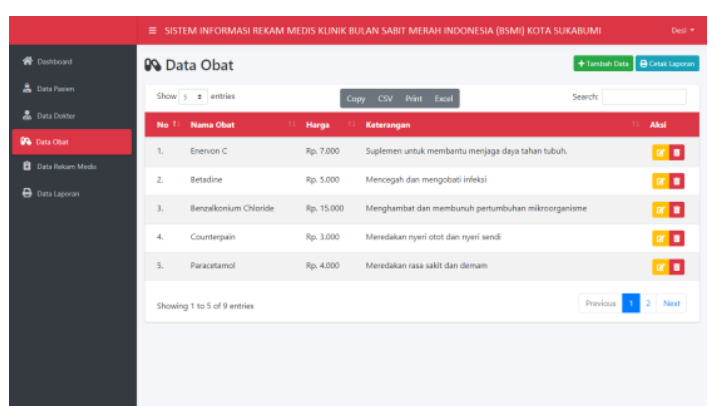

Gambar 12. Rancangan Antarmuka Data Obat

\section{Kesimpulan}

Berdasarkan pembahasan yang telah dilakukan, maka dapat diambil beberapa kesimpulan dalam penelitian ini sebagai berikut:

A. Sistem informasi rekam medis klinik BSMI Kota Sukabumi memudahkan pasien dalam melakukan pendaftaran dan melihat riwayat diagnosa hasil pemeriksaan.

B. Sistem informasi rekam medis klinik BSMI Kota Sukabumi dilengkapi dengan fitur kelola rekam medis, sehingga memudahkan untuk dokter dalam melakukan penanganan lebih lanjut.

C. Pencarian data pasien, data dokter dan data obat lebih mudah dan cepat sehingga lebih efisien dalam melakukan laporan.

Berdasarkan pembahasan yang telah dilakukan pada bab-bab sebelumnya, maka dapat diambil beberapa saran dari penelitian ini, yaitu:

A. Perlu adanya pelatihan bagi karyawan/petugas/sumber daya untuk mengelola sistem informasi rekam medis klinik BSMI Kota Sukabumi agar pengoperasian berjalan lancar.

B. Lakukan backup data secara rutin dan tingkatkan keamanan dari sistem agar data tidak disalahgunakan oleh pihak yang tidak bertanggung jawab.
C. Untuk penelitian lebih lanjut, sistem informasi rekam medis klinik BSMI Kota Sukabumi dilengkapi dengan fitur-fitur lainnya, agar kemudahan akses informasi bisa terjaga.

\section{Daftar Pustaka}

[1] Rahman, Taufik, Lukman Hakim dan Okta Maya Sari. (2020). Sistem Informasi Rekam Medis pada Dinas Kesehatan Kabupaten Musirawas Berbasis Web Mobile. Jurnal Teknik Informatika Musirawas Vol. 5, No. 2 Desember 2020.

[2] Raihan, Faza Muhammad. (2021). Perancangan Sistem Informasi Rekam Medis pada Klinik Saffira Sentra Medika Batam. Jurnal SNATi Vol. 1, No. 1, 2021.

[3] Peraturan Menteri Kesehatan RI, No. 269/MENKES/PER/III/2008, diakses September 2021.

[4] Purnama, Benny dan Renny Afriani N. (2016). Analisis dan Perancangan Sistem Informasi Rekam Medis di Rumah Sakit TK. IV dr.Bratanata Jambi. Jurnal Manajemen Sistem Informasi Vol.1 No.2, Desember 2016 ISSN: 2540-8011.

[5] Santoso, Hari, Sugesti dan Notatema Anugrah G. (2021). Rancang Bangun Sistem Informasi Rekam Medis Berbasis Web. Journal of Technology Information Vol. 7, No. 1, Juni 2021, ISSN: 24802108.

[6] Karman, A. Sakka dan S. Saptaputra. (2016). Faktor-Faktor yang Berhubungan dengan Pemanfaatan Pelayanan Kesehatan bagi Masyarakat Pesisir Desa Bungin Permai Kecamatan Konawe Selatan. Jurnal Ilmu Mahasiswa: Kesehatan Masyarakat, Vol. 1, No. 3.

[7] Helling, Lydia Salvina, Endang Wahyudi dan Hasanudin. (2019). Siremis: Sistem Infomasi Rekam Medis Puskesmas Kecamatan Matraman Jakarta. Jurnal Ilmiah Penelitian dan Penerapan Teknologi Informasi Vol 3, No. 2 Agustus 2019. ISSN: 2580-409X.

[8] Ferdiansyah, Devy. (2018). Penerapan Konsep Model View Controller pada Rancang Bangun Sistem Informasi Klinik Kesehatan Berbasis Web. Jurnal Kajian Ilmiah, Vol. 18, No. 2, Mei. ISSN: 1410-9794, Hal. 195-205. 
[9] Putranto, Yehezkiel Yanu, Toni Wijarnako Adi Putra, fitro Nur Hakim. (2017). Rancang Bangun Sistem Informasi Rekam Medis Klinik Berbasis Web (Studi Kasus: Klinik Utama Meditama Semarang). Jurnal Informatika UPGRIS Vol. 3, No. 2.

[10] Akbar, Jihadul dan Ainul Yaqin. (2021). Sistem Informasi Rekam Medis Berbasis Web pada Klinik Risa Rafana Menggunakan Teknologi Extreme Porgramming. Infotek: Jurnal Informatika dan Teknologi Vol. 4, No. 2 Juli 2021, e-ISSN: 2614-8773.

[11] Ambler, Scott W. "An Introduction to Agile Modelling”. (2018). Agile Modelling Home Page.

[12] Al-Bahra, Ladjamudin. (2016). Analisis dan Desain Sistem Informasi. Yogyakarta: Graha Ilmu. 